УДК 316.334 .2

ТЮРИКОВ Александр Георгиевич - доктор социологических наук, профессор, руководитель департамента социологии, истории и философии Финансового университета при Правительстве РФ (125993, Россия, г. Москва, Ленинградский np-кт, 49; t-ag2013@уапdex.ru)

БОРОВИНСКИХ Ольга Сергеевна - заведующий учебно-научной социологической лабораторией департамента социологии, истории и философии Финансового университета при Правительстве РФ (125993, Россия, г. Москва, Ленинградский пр-кт, 49; zibrovaolga@gmail.com)

ГОЛУБЕВА Ксения Александровна - студентка факультета социологии и политологии, заместитель заведующего учебно-научной социологической лабораторией департамента социологии, истории и философии Финансового университета при Правительстве РФ (125993, Россия, г. Москва, Ленинградский пр-кт, 49; kseniaklepa@mail.ru)

КУНИЖЕВА Диана Анзоровна - студентка факультета социологии и политологии, главный специалист учебно-научной социологической лаборатории департамента социологии, истории и философии Финансового университета при Правительстве РФ (125993, Россия, г. Москва, Ленинградский np-кт, 49; diana_kunizheva@mail.ru

\title{
ФОРМИРОВАНИЕ СИСТЕМЫ ВНУТРЕННЕЙ И ВНЕШНЕЙ НЕЗАВИСИМОЙ ОЦЕНКИ КАЧЕСТВА ОБРАЗОВАТЕЛЬНЫХ УСЛУГ В ВУЗЕ
}

\begin{abstract}
Аннотация. Одной из первоочередных задач высших учебных заведений является формирование и предоставление качественных образовательных услуг, отвечающих Федеральным государственным стандартам высшего профессионального образования и одновременно профессиональным стандартам, утвержденным Министерством труда. В статье рассматривается вопрос формирования системы оценки качества образовательных услуг не только на основе объективных показателей, но и с учетом мнения заинтересованных групп и участников образовательного процесса. В работе отражены результаты комплексного социологического исследования, включающего в себя массовый опрос преподавателей, студентов, молодых специалистов (выпускников) ${ }^{1}$ и экспертный опрос работодателей, который направлен на выявление оценки качества образовательных услуг на основе компетентностного подхода.

Ключевые слова: образовательные услуги, оценка качества, универсальные компетенции, личностнопрофессиональные компетенции, компетентностный подход, внутренняя и внешняя независимая оценка качества образовательных услуг
\end{abstract}

Д ля обеспечения высокого качества образовательных услуг и эффективности управления системой образования в целом необходимо изучать не только объективные показатели, но и мнения непосредственно заинтересованных групп и участников образовательного процесса. Поэтому возрастает интерес научного сообщества и представителей рынка труда к вопросам методики измерения качества образовательных услуг.

Проведенный анализ научной литературы и документальных источников позволяет выделить следующие основные теоретические подходы к исследованию качества образовательных услуг. Во-первых, это системный подход, включающий в себя оценку качества образовательных услуг как совокупности составляющих их элементов, образовательных подсистем, таких как содержание и условия учебного процесса, учебно-методическое обеспечение, профессорско-преподавательский состав и т.д. [Кузьмина 1970; Айрапетова, Рубина 2000; Руткевич 2007; Шереги, Савинков 2011]. Во-вторых, это процессный подход, в рамках которого оценка осуществляется с точки зрения последова-

\footnotetext{
${ }^{1}$ Исследование проводилось на примере Финансового университета при Правительстве РФ в 2018 г.
} 
тельности исполнения функций, операций, направленных на создание результата, имеющего ценность для потребителя [Третьяков 2001; Поташник 2005; Шамова 2008]. В-третьих, это компетентностный подход, который подразумевает оценку сформированности определенного набора компетенций как конечного результата процесса обучения [Краевский 2000; Лебедев 2014; Большунов, Тюриков 2018].

В силу сложившейся практики и специфики взаимодействия субъектов образовательного пространства и рынка труда, а также возможностей социологического инструментария измерения качества целесообразно использовать компетентностный подход к оценке качества образовательных услуг. Преимуществом такого подхода является возможность оценки качества и востребованности компетенций на рынке труда независимыми субъектами и возможность их уровневого измерения. Также эта методика позволяет сравнить как внешнюю, так и внутреннюю независимую оценку качества образовательных услуг через перечень конкретных базовых личностно-профессиональных и надпрофессиональных, универсальных компетенций, приобретенных в процессе обучения.

Методика. На первом этапе научно-исследовательской работы была разработана концептуальная и операциональная модель внутренней и внешней независимой оценки качества образовательных услуг, на втором этапе проведен экспертный опрос, в результате которого был определен тот континуум компетенций, который необходим любому специалисту, выходящему на рынок труда. Исходя из этого, перечень компетенций разделен на две группы: универсальные (soft skills) и профессиональные (hard skills) (см. табл. 1).

Далее, на третьем этапе для проведения внутренней и внешней независимой оценки качества образовательных услуг было реализовано комплексное исследование, включающее в себя 3 ступени:

1) опрос преподавателей и студентов (выборочная совокупность $N=510$ );

2) опрос работодателей и выпускников (выборочная совокупность $N=1260$ );

3) контент-анализ требований по вакансиям на рынке труда (более 2000 запросов по 18 профессиональным профилям).

Результаты. Одним из видов анализа, включенного в комплексный исследовательский проект, реализованный в рамках выполнения научной работы, являлось проведение контент-анализа рекрутинговых сайтов и $I T$-сервисов по подбору персонала и поиску работы. Среди наиболее крупных российских компаний интернет-рекрутмента были охвачены такие, как HeadHunter, SuperJob, Работа.ру, Карьерист.ру и др.

Предметом анализа данной методики исследования в вопросах качества образовательных услуг была база, состоящая более чем из 2000 вакансий работодателей, которая отражала перечень требований к соискателям и их ожидаемые компетенции, необходимые для выполнения того или иного вида трудовой деятельности. Единицами анализа являлись вакансии, связанные непосредственно с выполнением профессиональной деятельности. Единицей счета обозначена частота упоминания тех или иных требований к кандидату (компетенций). Таким образом, для дальнейшего проведения контент-анализа требований в вакансиях было обозначено 18 профессий (таких, как маркетолог, юрист, аудитор, кредитный эксперт, финансовый аналитик, сотрудник в сфере налогообложения и т.д.).

Проведенный анализ позволил составить обобщенный портрет запроса (требования и ожидания) работодателей от своих потенциальных сотрудников. Собранные требования были разделены на две крупные группы описанных выше компетенций - профессиональные знания и умения и универсальные навыки. 


\section{Перечень необходимых компетенций специалиста, полученный по результатам экспертного опроса}

\begin{tabular}{|c|c|}
\hline Универсальные компетенции (soft skills) & Профессиональные компетенции (hard skills) \\
\hline Способность работать в команде & $\begin{array}{l}\text { Профессиональная грамотность и } \\
\text { способность применять знания на } \\
\text { практике }\end{array}$ \\
\hline Нацеленность на результат & $\begin{array}{l}\text { Понимание проектной деятельности, } \\
\text { навыки работы с проектами }\end{array}$ \\
\hline $\begin{array}{l}\text { Умение управлять временем и другими } \\
\text { ресурсами для решения поставленных } \\
\text { задач }\end{array}$ & $\begin{array}{l}\text { Умение пользоваться } \\
\text { специализированными компьютерными } \\
\text { программами }\end{array}$ \\
\hline Организаторские навыки & $\begin{array}{l}\text { Знание современных технологий в } \\
\text { профессиональной деятельности }\end{array}$ \\
\hline $\begin{array}{l}\text { Системное, стратегическое, аналитическое } \\
\text { мышление }\end{array}$ & $\begin{array}{l}\text { Навыки деловой переписки и делового } \\
\text { общения, умение работать с документацией }\end{array}$ \\
\hline $\begin{array}{l}\text { Умение быстро ориентироваться в } \\
\text { различных предметных областях }\end{array}$ & Знание иностранного языка \\
\hline Готовность к ведению переговоров & $\begin{array}{l}\text { Умение пользоваться информационными } \\
\text { ресурсами }\end{array}$ \\
\hline Обладание стрессоустойчивостью & $\begin{array}{l}\text { Способность к планированию и } \\
\text { организации профессиональной } \\
\text { деятельности }\end{array}$ \\
\hline Наличие креативного мышления & $\begin{array}{l}\text { Способность профессионально } \\
\text { обосновывать и отстаивать свою позицию в } \\
\text { различных деловых ситуациях }\end{array}$ \\
\hline \multicolumn{2}{|l|}{$\begin{array}{l}\text { Коммуникабельность, умение работать с } \\
\text { людьми }\end{array}$} \\
\hline \multicolumn{2}{|l|}{ Адаптивность } \\
\hline \multicolumn{2}{|l|}{$\begin{array}{l}\text { Управление саморазвитием, } \\
\text { самообучаемость }\end{array}$} \\
\hline \multicolumn{2}{|l|}{ Самоконтроль } \\
\hline $\begin{array}{l}\text { Инициативность, активная жизненная } \\
\text { позиция }\end{array}$ & \\
\hline
\end{tabular}

Анализ данных показал, что среди универсальных компетенций наиболее востребованными оказались группы компетенций, отражающих черты характера и отношение к работе. Для рынка труда каждый кандидат вне зависимости от направления его подготовки должен уметь работать с большим объемом информации и ориентироваться на результат.

При поиске сотрудника в группе коммуникационных навыков выделялись два основных требования. Во-первых, грамотная устная и письменная речь, во-вторых, коммуникабельность, более связанная с личностной характеристикой человека.

Наибольшую востребованность среди профессиональных компетенций у работодателей вызывают профессиональные знания, умения и навыки, владение ПК и программами, опыт работы, способность профессионально обосновывать и отстаивать свою позицию в различных деловых ситуациях. 
Следующим по востребованности блоком компетенций у работодателей выступает умение владеть ПК и программами. Данный блок включает в себя обязанность обладать знаниями по пользованию ПК и работе в ряде систем и программ, среди которых Microsoft Office (Word, Excel, Power Point, Visio), программное обеспечение $1 C$, правовые электронные базы данных (Консультант Плюс, Гарант), системы управления базами данных (SAP, MS SQL, Oracle), системы электронного документооборота.

Полученные данные свидетельствуют о том, что при приеме на работу работодатель отводит значительное внимание стажу работы соискателя. Ожидаемый опыт работы потенциального сотрудника в годах был определен для разных профилей по-разному. В целом по всем анализируемым вакансиям требуются кандидаты с опытом работы до 6 лет.

В методике была учтена оценка не только внешнего, но и внутреннего образовательного рынка, где свои компетенции, полученные в вузе, оценивали студенты выпускных курсов бакалавриата и магистратуры, а также преподаватели, которые оценивали компетенции своих коллег. Следующим этапом исследований стал массовый опрос выпускников последних 5 лет об их уровне владения компетенциями, полученными в вузе, и экспертный опрос работодателей, где они ставили оценку сформированным компетенциям молодых специалистов, принятых на работу за последние 5 лет.

Далее, для точного и быстрого выявления связи между явлениями в ходе анализа компетенций, оцененных заинтересованными группами в лице выпускников, работодателей, преподавателей и студентов, был использован индексный метод. Основным преимуществом данного анализа является возможность сравнения разнородного материала, т.к. индекс представляет собой относительную величину, используемую для характеристики элементов явления, которые нельзя суммировать.

Модель расчета индексных показателей характеризуется реализацией исследовательских действий на нескольких этапах. Индексное значение рассчитано путем нормирования результатов одномерного распределения $\mathrm{K}$ «1». Максимальное значение - «1», минимальное значение - «0».

В рамках рейтингования компетенций последовательность расположения того или иного знания, навыка и умения определена рангом, который присвоен в соответствии с усредненным нормированным значением. Усредненное нормированное значение было рассчитано на основе выведения средней из нормированных значений по оценкам преподавателей, студентов, работодателей и выпускников. Специфика ранговой шкалы заключается в том, что чем выше ранговое значение, присвоенное той или иной компетенции, тем больше оно сформировано в вузе и наоборот.

Также на основе индексных значений сконструирована уровневая шкала. Процесс построения уровневой шкалы состоит из нескольких последовательных действий:

- определяются максимальное и минимальное значения по нормированному индексу с последующим отбрасыванием данных крайних значений, что устанавливает работающую часть шкалы;

- производится расчет величины работающей части шкалы, которая определяется разностью между максимальным значением обозначенной части шкалы и ее минимальным значением;

- задается число уровней и устанавливается величина шага шкалы (посредством отношения величины работающей части шкалы и числом уровней). Устанавливаемое число уровней определяется исследователем. Например, 
трехуровневый метод классифицирует индексные значения по трем категориям: высокий уровень, средний и низкий.

Определение уровня выделенных компетенций осуществлялось посредством следующей трехуровневой шкалы: высокий уровень индексного показателя принимается при значении от 0,7341 и выше; средний уровень - от 0,7342 до 0,6668; низкий уровень - от 0,6667 и ниже.

Таким образом, представленный набор навыков и умений, вошедших в категорию с низким уровнем сформированности компетенций, свидетельствует о недостаточной подготовке и обладании данными компетенциями, несмотря на их востребованность. На это и должны обратить внимание вузы при предоставлении образовательных услуг обучающимся и будущим молодым специалистам.

Таким образом, полученная оценка качества образовательных услуг по результатам проведенного исследования свидетельствует, что сегодня существует разрыв между требованиями к профессиональным компетенциям, которые предъявляются работодателем к выпускникам вузов, и оценкой уровня их сформированности у преподавателей и студентов вузов. Более того, почти в 2 раза ниже оценивают сформированность своих профессиональных и надпрофессиональных компетенций выпускники (устраивающиеся на работу в течение 5 лет после окончания вуза), чем студенты выпускного курса и преподаватели. Это свидетельствует о завышенных оценках сформированности компетенций в период обучения в вузе и о потенциальных разрывах в ожиданиях при реальном устройстве на работу. На это и должны обратить внимание вузы при предоставлении образовательных услуг обучающимся - будущим молодым специалистам. Разработанная и апробированная система независимого внутреннего контроля качества образовательных услуг показала свою релевантность и может быть распространена в целом на федеральную и региональную систему высшего образования Российской Федерации.

Статья подготовлена по результатам исследований, выполненныхза счет бюджетныхсредств погосударственному заданию Финансовому университету при Правительстве Российской Федерации на 2018 г.

\section{Список литературы}

Айрапетова С.Н., Рубина Л.Я. 2000. Может ли социология помочь в формировании социального заказа на образование? - Социс. Социологические исследования. № 5. С. 81-89.

Большунов А.Я., Тюриков А.Г. 2018. Формирование профессиональной субъектности как критерия качества высшего образования. - Инновации в образовании. № 11. С. 45-52.

Краевский В. В. 2000. Содержание образования - бег на месте. - Педагогика. № 7. C. 3-12.

Кузьмина Н.В. 1970. Методы исследования педагогической деятельности. Л.: Изд-во Ленингр. ун-та. 114 с.

Лебедев О.Е. 2014. Управление образовательным процессом: как оценивать образовательные результаты. - Народное образование. № 1. С. 56-61.

Поташник М.М. 2005. Программа развития школы, достойная бюджетного гранта. - Народное образование. № 8. С. 73-88.

Руткевич М.Н. 2007. Образованность в постсоветской России: противоречивость процесса. - Социс. Социологические исследования. № 12. С. 13-21.

Третьяков П.И. 2001. Профессиональное образовательное учреждение: управ- 
ление образованием по результатам: практика педагогического менеджмента. М.: Новая школа. 368 с.

Шамова Т.И. 2008. Методологические основы управления становлением и развитием системы оценивания качества образовательного процесса в вузе. Педагогическое образование и наука. № 5. С. 40-46.

Шереги Ф.Э., Савинков В.И. 2011. Образование как фактор формирования интеллектуального потенциала России. М.: ЦСПиМ. 288 с.

TYURIKOV Aleksandr Georgievich, Dr.Sci. (Soc.), Professor, Head of the Department of Sociology, History and Philosophy, Financial University under the Government of the Russian Federation (49 Leningradsky Ave, Moscow, Russia, 125993; t-ag2013@yandex.ru)

BOROVINSKIKH Ol'ga Sergeevna, Head of the Educational-scientific Sociological Laboratory, Department of Sociology, History and Philosophy, Financial University under the Government of the Russian Federation (49 Leningradsky Ave, Moscow, Russia, 125993; zibrovaolga@gmail.com)

GOLUBEVA Kseniya Aleksandrovna, student of Faculty of Sociology and Political Science, Deputy Head of Educationalscientific Sociological Laboratory, Department of Sociology, History and Philosophy, Financial University under the Government of the Russian Federation (49 Leningradsky Ave, Moscow, Russia, 125993; kseniaklepa@mail.ru) KUNIZHEVA Diana Anzorovna, student of Faculty of Sociology and Political Science, Chief Specialist of Educationalscientific Sociological Laboratory, Department of Sociology, History and Philosophy, Financial University under the Government of the Russian Federation (49 Leningradsky Ave, Moscow, Russia, 125993; diana_kunizheva@mail.ru)

\title{
FORMATION OF THE SYSTEM OF INTERNAL AND EXTERNAL INDEPENDENT ESTIMATE OF EDUCATIONAL SERVICES QUALITY IN HIGHER INSTITUTION
}

\begin{abstract}
One of the priorities of higher education institutions is the formation and provision of high-quality educational services that meet Federal State Standards of Higher Professional Education and professional standards approved by the Ministry of Labor. The article considers the issue of forming a system for assessing the quality of educational services not only on the base of objective indicators, but also taking into account the views of interested groups and participants of the educational process. The paper reflects the results of a comprehensive sociological research, which includes a mass survey of teachers, students, young professionals (graduates) and an expert survey of employers, which is aimed at identifying assessments of the quality of educational services based on the competence approach.
\end{abstract}

Keywords: educational services, quality assessment, universal competence, personal and professional competence, competence approach, internal and external independent assessment of quality of educational services 